\title{
Analysis of the Maximum Straight Line Length for Prairie Highway using Driver's Heart Rate Variability
}

\author{
Yueying Huo, Wenquan $\mathrm{Li}^{*}$ \\ School of Transportation, Southeast University, NO.2 Sipailou \\ Nanjing, 210096, P. R. China \\ Jinhua Zhao \\ Department of Civil Engineering, University of British Columbia, \#2007 - 6250 Applied Science Lane \\ Vancouver, BC V6T 1Z4, Canada \\ Shoulin Zhu \\ College of Energy and Transport Engineering, Inner Mongolia Agricultural University, NO.306 Zhaowudalu \\ Hohhot, 010018, P. R. China \\ Received: 09-03-2011 \\ Accepted: 19-04-2011
}

\begin{abstract}
The attention of driver traveling along a long straight line of prairie highway is easy to be distracted. In this paper, the correlation of straight line length and driver's attention is studied through laboratory simulation experiment and regression analysis. It can be theoretically concluded that the maximum straight line length for prairie highway within which the driver could travel with proper attention is $5 \mathrm{~km}$. This study is significant both for prairie highway construction and Intelligent Transportation System.
\end{abstract}

Keywords: Prairie highway, the Maximum straight line length, Driver’s attention, Heart rate variability

\section{Introduction}

Prairie is widely distributed in Inner Mongolia in China, natural prairie area is 86667 thousands hectares, which account for $73.26 \%$ of the total land area of Inner Mongolia. The terrain is flat, and the landscape is monotonous in prairies. The main particularity of prairie highway is long straight line.

The straight line of prairie highway is over-long and monotonous, the attention of driver traveling along it is easy to be distracted. Under this condition, a traffic accident may take place in case of urgent situations, because the driver almost has no time to react, so the straight line length is suggested to be limited.

The long straight line has negative effect on safe driving and the maximum straight line length should be limited, which have become consensus in road engineering academia. $^{1-3}$ At present, recommendation value of the maximum straight line length is stipulated according to experience and survey, relevant theoretical research is few and far between. The maximum straight line length (in meter) in Japan, Germany and China is suggested to be 20 times of the design speed (in kilometre per hour) at most; the recommendation value of it respectively is $8 \mathrm{~km}$ and $4.83 \mathrm{~km}$ in the former Soviet Union and United States; France deems that the long straight line should be replaced by using large radius curve of $5 \mathrm{~km}$ to $15 \mathrm{~km}$. ${ }^{4,5}$ Refs.1,2 brought forward the restricted models of the maximum straight line length for different horizontal alignment combinations, which based on that the maximum traveling time was 70s along the straight line. ${ }^{1,2}$ Ref.6 suggested the maximum straight line length

* corresponding author: wenqli@seu.edu.cn 
for freeway was $4.2 \mathrm{~km}{ }^{6}$

Ref.7 brought forward new theory of road alignment design in the early 1990s, the new theory emphasizes that road alignment design should base on road user's traffic demand and feature of psychological and physiological reaction theoretically. ${ }^{7}$ At present, there are many literatures applying the new theory to study alignment of freeway and mountainous highway, most literatures focus on studying curve's radius and gradient, ${ }^{8-13}$ and physiological index heart rate is frequently studied. ${ }^{8-11,14,15}$

Vehicle monitoring system, as portion of the Intelligent Transportation Systems which applies state-of-the-art information technologies to provide more efficient and effective solutions to current traffic congest and traffic safety problems, ${ }^{16-18}$ detects road environment, vehicle condition and driver condition, and alert the driver under potential safety hazard. The maximum straight line length could be an input to vehicle monitoring system, i.e. if vehicle monitoring system detects that the straight line length reaches the maximum, it will alert the driver to make the driver's attention centralized.

This paper intends to study the maximum straight line length for prairie highway. The maximum straight line length can guarantee that the driver could travel with proper attention within it. In this paper, new theory of road alignment design is applied to study the maximum straight line length, and driver's physiological index heart rate variability is selected for the purpose because heart rate variability can indicate the driver's attention level. Laboratory simulation experiment is carried out to study the correlation between the straight line length and driver's attention.

\section{Laboratory Simulation Experiment Introduction}

\subsection{Method and equipments for laboratory simulation experiment}

The driver watches the straight line editing video (Fig.1 showing), which simulates the real situation of the driver traveling along the straight line of prairie highway, and electrocardiosignals (ECG) of driver are acquired using RM6240B multi-channel physiological signal acquisition system (Fig.2 showing) at the same time. Acquisition interface of ECG signals is shown in Fig.3, the first column displays electrooculogram (EOG) which has not been studied in this paper, and the second column displays ECG. The straight line editing video is recorded in the field experiment and the speed of test vehicle traveling along the straight line of prairie highway is $80 \mathrm{~km} / \mathrm{h}$. The experiment road is $10 \mathrm{~km}$, and its gradient is between $0 \%$ and $1 \%$. The simulation traveling time is 7.5min. This simulation experiment selects 11 drivers, and each driver has 30min pre-driving.

The simulation experiment equipments include a RM6240B multi-channel physiological signal acquisition system (Fig.4 showing), a desk-top computer, a notebook computer, and a projector.

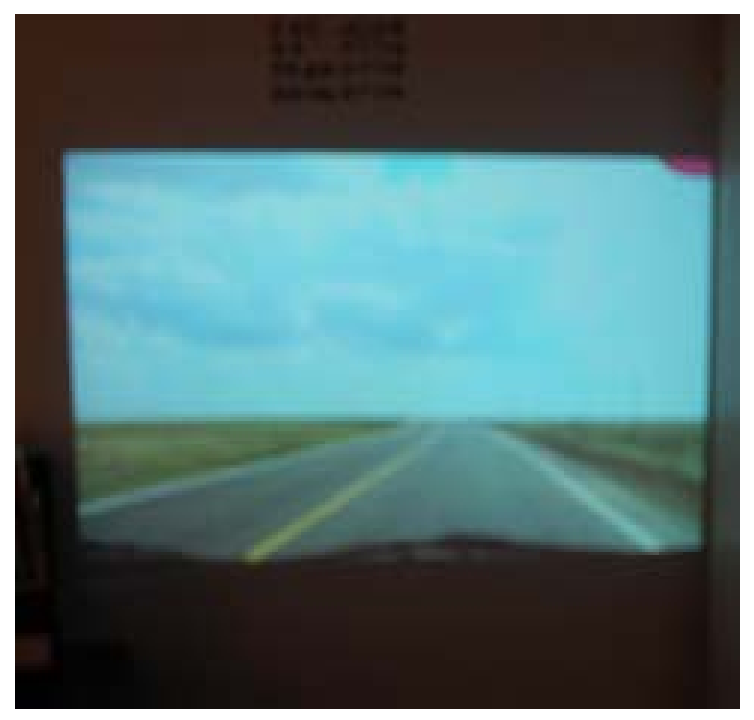

Fig.1. The straight line editing video

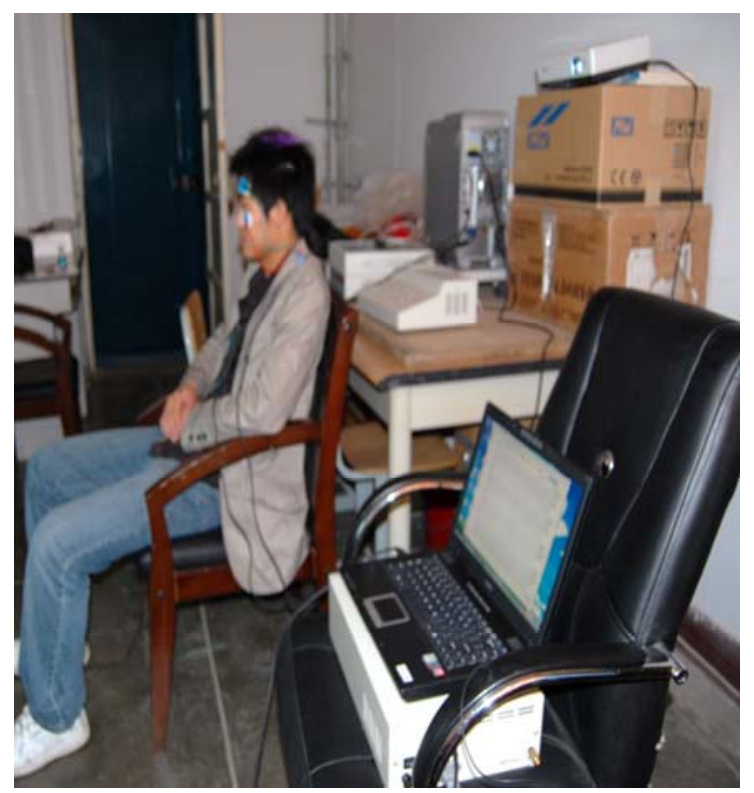

Fig.2. The scene of laboratory simulation experiment 


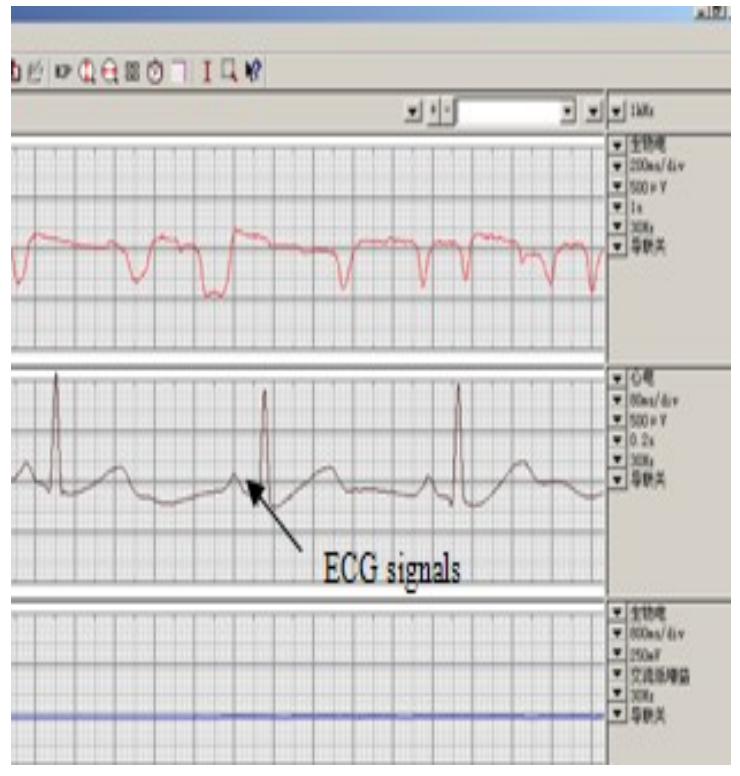

Fig.3. The acquisition interface of ECG signals

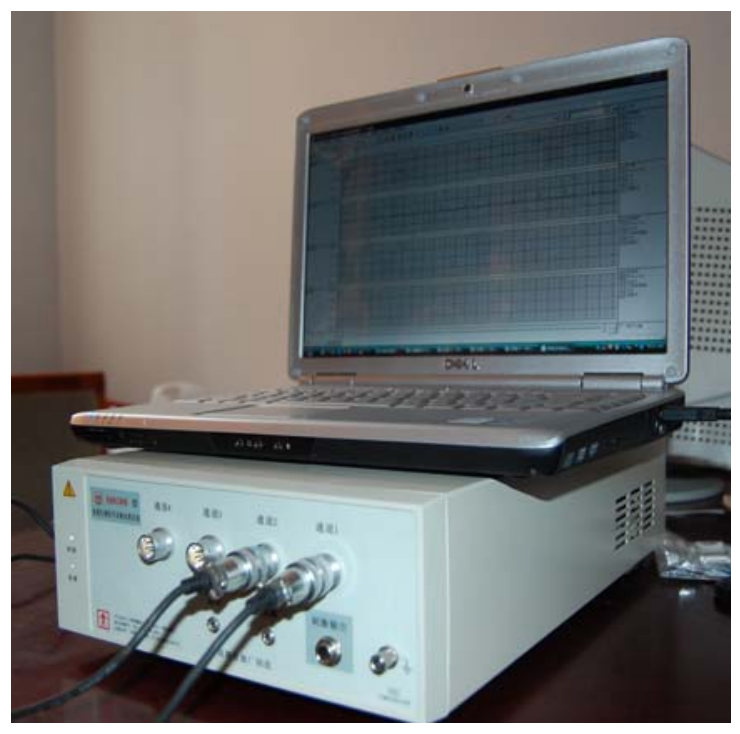

Fig.4. Multi-channel physiological signal acquisition system

\subsection{Feasibility for laboratory simulation experiment}

The attention of driver traveling along the straight line of prairie highway is influenced by road condition such as alignment and pavement, traffic condition such as traffic volume, climate condition, and vehicle driving condition.
This paper focuses on the effect of straight line length on driver's attention, so road alignment is the only concern among these factors, and other influence should be eliminated.

Straight line editing video is provided with consistent ecological environment, fair running pavement, and no other vehicles, so it can ensure that the effect of pavement condition, traffic condition and climate condition on driver's attention is eliminated. Besides, the driver has not operation behavior, so the effect of vehicle driving condition such as shock and jolt on driver's attention is also eliminated. Laboratory simulation experiment ensures that the driver's attention is only influenced by the road alignment, and creates ideal condition for this study, so it is feasible for theoretically studying the straight line length.

\subsection{Data processing for laboratory simulation experiment}

Heart rate variability (HRV) describes the phenomenon of successive heartbeat interval's fluctuation, ${ }^{19,20}$ it reflects neurohumoral factors on the regulation of sinus node, and also reflects autonomous nervous system's activity and coordination relation. ${ }^{21-23}$ HRV can be studied through analyzing successive RR interval's diversification. ${ }^{24}$ HRV's analysis methods include time domain analysis, frequency domain analysis and nonlinear analysis. ${ }^{25}$ Time domain analysis is using statistics and geometry to analyze RR interval with chronological order, and is used in this paper. Time domain analysis involves many indicators, SDNN, SDSD, PNN50 are only studied in this paper, and are explained as follows ${ }^{26,27}$ :

- SDNN (ms): RR interval's standard deviation of normal sinus

$$
S D N N=\sqrt{\frac{\sum_{i=1}^{N}\left(R R_{i}-\text { meanRR }\right)^{2}}{N} .}
$$

- $\quad S D S D$ (ms): adjacent RR interval difference's standard deviation

$$
S D S D=\sqrt{\frac{\sum_{i=1}^{N-1}\left[\left(R R_{i+1}-R R_{i}\right)-\frac{\left(R R_{i+1}-R R_{i}\right)}{N-1}\right]^{2}}{N-1} .}
$$

- PNN50 (\%): the percentage that the number of RR interval whose difference with adjacent RR interval 
is greater than $50 \mathrm{~ms}$ accounts for the RR interval total number.

Where: $N$ represents total number of RR interval; $R R_{i}$ represents NO.i RR interval; meanRR represents mean of all the RR intervals; $R R_{i+1}$ represents $N O . i+1$ RR interval.

RR intervals are exported from ECG signals using matching software of RM6240B multi-channel physiological signal acquisition system. According to above formulas, SDNN, SDSD , PNN50 of 11 drivers are computed taking $1 \mathrm{~min}$ as statistical unit (the last one takes $0.5 \mathrm{~min}$ as statistical unit), and then compute the arithmetic mean value of 11 drivers.

\section{Regression Analysis between the Straight Line Length and $S D N N$, SDSD , PNN50}

In this paper, regression analysis between the straight line length and $S D N N, S D S D, P N N 50$ is carried out to quantificationally study the correlation of the straight line length and driver's attention. In the selected straight line editing video, the traveling speed is $80 \mathrm{~km} / \mathrm{h}$, the simulation journey can be calculated according to this speed and the traveling time. The traveling time takes $1 \mathrm{~min}$, 2min, 3min, $4 \mathrm{~min}$, $5 \mathrm{~min}$, $6 \mathrm{~min}$, $7 \mathrm{~min}$, $7.5 \mathrm{~min}$ as parameters, in accordance with them, the straight line length respectively is $1.33 \mathrm{~km}, 2.67 \mathrm{~km}, 4 \mathrm{~km}, 5.33 \mathrm{~km}$, $6.67 \mathrm{~km}, 8 \mathrm{~km}, 9.33 \mathrm{~km}, 10 \mathrm{~km}$.

\subsection{Regression model between the straight line length and $S D N N$}

Tab.1 shows the data of the straight line length and $S D N N$. The scatter diagram regarding the straight line length as a independent variable and $S D N N$ as a dependent variable shows a parabolic curve with upward opening, so curve estimation with quadratic model is analyzed via software SPSS. Regression analysis outputs are showed in Tab.2-Tab.4.

Regression model between the straight line length of prairie highway and $S D N N$ of the driver is displayed as Eq. (3),

Tab.1. Data of straight line length and SDNN

\begin{tabular}{ccccccccc}
\hline $\begin{array}{c}\text { straight } \\
\begin{array}{c}\text { line } \\
\text { length } \\
(\mathrm{km})\end{array}\end{array}$ & 1.33 & 2.67 & 4.00 & 5.33 & 6.67 & 8.00 & 9.33 & 10.00 \\
\hline $\begin{array}{c}S D N N \\
(\mathrm{~ms})\end{array}$ & 48.12 & 43.87 & 34.37 & 35.53 & 3725 & 3822 & 39.65 & 38.98 \\
\hline
\end{tabular}

Tab.2. The determinant coefficient of regression model 1

\begin{tabular}{ccccc}
\hline Model & $\mathrm{R}$ & $\begin{array}{c}\mathrm{R} \\
\text { Square }\end{array}$ & $\begin{array}{c}\text { Adjusted } \mathrm{R} \\
\text { Square }\end{array}$ & $\begin{array}{c}\text { Std. Error of the } \\
\text { Estimate }\end{array}$ \\
\hline 1 & 0.890 & 0.792 & 0.709 & 2.434 \\
\hline
\end{tabular}

Tab.3. The anova of regression model 1

\begin{tabular}{cccccc}
\hline Model 1 & $\begin{array}{c}\text { Sum of } \\
\text { Squares }\end{array}$ & df & $\begin{array}{c}\text { Mean } \\
\text { Square }\end{array}$ & F & Sig. \\
\hline Regression & 112.781 & 2 & 56.391 & 9.519 & 0.020 \\
Residual & 29.618 & 5 & 5.924 & & \\
Total & 142.400 & 7 & & & \\
\hline
\end{tabular}

Tab.4. The regression coefficient of regression model 1

\begin{tabular}{|c|c|c|c|c|c|}
\hline \multirow[t]{2}{*}{ Model 1} & \multicolumn{2}{|c|}{$\begin{array}{l}\text { Unstandardized } \\
\text { Coefficients }\end{array}$} & \multirow{2}{*}{$\begin{array}{c}\text { Standardized } \\
\text { Coefficients } \\
\text { Beta }\end{array}$} & \multirow[t]{2}{*}{$\mathrm{t}$} & \multirow[t]{2}{*}{ Sig. } \\
\hline & B & $\begin{array}{l}\text { Std. } \\
\text { Error }\end{array}$ & & & \\
\hline $\mathrm{L}$ & -5.839 & 1.431 & -4.060 & -4.079 & 0.010 \\
\hline $\mathrm{L}^{* * 2}$ & 0.446 & 0.121 & 3.658 & 3.676 & 0.014 \\
\hline Constant & 54.584 & 3.565 & & 15.309 & 0.000 \\
\hline
\end{tabular}

$$
S D N N=0.446 L^{2}-5.839 L+54.584, \bar{R}^{2}=0.709 .
$$

In Eq. (3), SDNN represents RR interval's standard deviation, $L$ represents the straight line length of prairie highway, $\bar{R}^{2}$ represents adjusted $R$ square, applicable scope of the model is that $L$ occurs between 0 and $10 \mathrm{~km}$.

- Testing goodness of fit of regression model: according to Tab.2, $\bar{R}^{2}=0.709$, Eq. (3) fits sample data well.

- Significance testing of regression model: according to Tab.3, Sig. is 0.020 , and less than significance level 0.05 , so Eq. (3) is statistically significant at significance level of 0.05 , and can be used to describe the correlation between the straight line length and SDNN .

- Significance testing of regression coefficient: according to Tab.4, Sig. of $L$ is 0.010 and Sig. of $L^{2}$ is 0.014 , they are both less than 0.05 , so each coefficient is statistically significant, i.e. the effect of $L$ and $L^{2}$ on SDNN is significant.

\subsection{Regression model between the straight line length and $S D S D$}

Tab.5 shows the data of the straight line length and SDSD. The scatter diagram regarding the straight line length as a independent variable and $S D S D$ as a 
dependent variable shows a parabolic curve with upward opening, so curve estimation with quadratic model is analyzed via software SPSS. Regression analysis outputs are showed in Tab.6-Tab.8.

Regression model between the straight line length of prairie highway and $S D S D$ of the driver is established as Eq. (4),

$S D S D=0.169 L^{2}-1.753 L+34.285, \bar{R}^{2}=0.675$.

In Eq. (4), SDSD represents adjacent RR interval difference's standard deviation, $L$ represents the straight line length of prairie highway, $\bar{R}^{2}$ represents adjusted $R$ square, applicable scope of the model is that $L$ occurs between 0 and $10 \mathrm{~km}$.

Tab.5. Data of straight line length and SDSD

\begin{tabular}{ccccccccc}
\hline $\begin{array}{c}\text { straight } \\
\begin{array}{c}\text { line } \\
\text { length } \\
(\mathrm{km})\end{array}\end{array}$ & 1.33 & 2.67 & 4.00 & 5.33 & 6.67 & 8.00 & 9.33 & 10.00 \\
\hline $\begin{array}{c}S D S D \\
(\mathrm{~ms})\end{array}$ & 31.65 & 3238 & 29.19 & 29.03 & 30.38 & 31.45 & 3285 & 33.36 \\
\hline
\end{tabular}

Tab.6. The determinant coefficient of regression model 2

\begin{tabular}{ccccc}
\hline Model & $\mathrm{R}$ & $\begin{array}{c}\mathrm{R} \\
\text { Square }\end{array}$ & $\begin{array}{c}\text { Adjusted R } \\
\text { Square }\end{array}$ & $\begin{array}{c}\text { Std. Error of the } \\
\text { Estimate }\end{array}$ \\
\hline 2 & 0.876 & 0.768 & 0.675 & 0.926 \\
\hline
\end{tabular}

Tab.7. The anova of regression model 2

\begin{tabular}{cccccc}
\hline Model 2 & $\begin{array}{c}\text { Sum of } \\
\text { Squares }\end{array}$ & df & $\begin{array}{c}\text { Mean } \\
\text { Square }\end{array}$ & F & Sig. \\
\hline Regression & 14.151 & 2 & 7.075 & 8.253 & 0.026 \\
Residual & 4.286 & 5 & 0.857 & & \\
Total & 18.437 & 7 & & & \\
\hline
\end{tabular}

Tab.8. The regression coefficient of regression model 2

\begin{tabular}{cccccc}
\hline \multirow{2}{*}{ Model 2 } & \multicolumn{2}{c}{ Unstandardized } \\
& Coefficients & \multicolumn{2}{c}{$\begin{array}{c}\text { Standardized } \\
\text { Coefficients }\end{array}$} & t & Sig. \\
& B & Std. & Beta & & \\
& & Error & & & \\
\hline L & -1.753 & 0.545 & -3.387 & -3.219 & 0.023 \\
L $^{* * 2}$ & 0.169 & 0.046 & 3.849 & 3.659 & 0.015 \\
Constant & 34.285 & 1.356 & & 25.277 & 0.000 \\
\hline
\end{tabular}

- Testing goodness of fit of regression model: according to Tab.6, $\bar{R}^{2}=0.675$, Eq. (4) fits sample data well.
- Significance testing of regression model: according to Tab.7, Sig. is 0.026 , and less than significance level 0.05 , so Eq. (4) is statistically significant at significance level of 0.05 , and can be used to describe the correlation between the straight line length and SDSD .

- Significance testing of regression coefficient: according to Tab.8, Sig. of $L$ is 0.023 and Sig. of $L^{2}$ is 0.015 , they are both less than 0.05 , so each coefficient is statistically significant, i.e. the effect of $L$ and $L^{2}$ on SDSD is significant.

\subsection{Regression model between the straight line length and $P N N 50$}

Tab.9 shows the data of the straight line length and $P N N 50$. The scatter diagram regarding the straight line length as a independent variable and PNN50 as a dependent variable shows a parabolic curve with upward opening, so curve estimation with quadratic model is analyzed via software SPSS. Regression analysis outputs are showed in Tab.10-Tab.12.

Tab.9. Data of straight line length and PNN50

\begin{tabular}{ccccccccc}
\hline $\begin{array}{c}\text { straight } \\
\begin{array}{c}\text { line } \\
\text { length } \\
(\mathrm{km})\end{array}\end{array}$ & 1.33 & 2.67 & 4.00 & 5.33 & 6.67 & 8.00 & 9.33 & 10.00 \\
\hline $\begin{array}{c}P N N 50 \\
(\%)\end{array}$ & 13.17 & 13.92 & 9.89 & 9.42 & 10.72 & 1217 & 13.08 & 1327 \\
\hline
\end{tabular}

Tab.10. The determinant coefficient of regression model 3

\begin{tabular}{ccccc}
\hline Model & $\mathrm{R}$ & $\begin{array}{c}\mathrm{R} \\
\text { Square }\end{array}$ & $\begin{array}{c}\text { Adjusted R } \\
\text { Square }\end{array}$ & $\begin{array}{c}\text { Std. Error of the } \\
\text { Estimate }\end{array}$ \\
\hline 3 & 0.813 & 0.661 & 0.526 & 1.182 \\
\hline
\end{tabular}

Tab.11. The anova of regression model 3

\begin{tabular}{cccccc}
\hline Model 3 & $\begin{array}{c}\text { Sum of } \\
\text { Squares }\end{array}$ & df & $\begin{array}{c}\text { Mean } \\
\text { Square }\end{array}$ & F & Sig. \\
\hline Regression & 13.634 & 2 & 6.817 & 4.880 & 0.067 \\
Residual & 6.984 & 5 & 1.397 & & \\
Total & 20.618 & 7 & & & \\
\hline
\end{tabular}

Regression model between the straight line length of prairie highway and PNN50 of the driver is established as Eq. (5),

$$
P N N 50=0.184 L^{2}-2.088 L+16.296, \bar{R}^{2}=0.526 .
$$


In Eq. (5), PNN50 represents the percentage that the number of RR interval whose difference with adjacent $\mathrm{RR}$ interval is greater than $50 \mathrm{~ms}$ accounts for the $\mathrm{RR}$ interval total number, $L$ represents the straight line length of prairie highway, $\bar{R}^{2}$ represents adjusted $R$ square, applicable scope of the model is that $L$ occurs between 0 and $10 \mathrm{~km}$.

Tab.12. The regression coefficient of regression model 3

\begin{tabular}{cccccc}
\hline Model 3 & \multicolumn{2}{c}{$\begin{array}{c}\text { Unstandardized } \\
\text { Coefficients }\end{array}$} & $\begin{array}{c}\text { Standardized } \\
\text { Coefficients }\end{array}$ & $\mathrm{t}$ & Sig. \\
& $\mathrm{B}$ & $\begin{array}{c}\text { Std. } \\
\text { Error }\end{array}$ & Beta & & \\
\hline $\mathrm{L}$ & -2.088 & 0.695 & -3.815 & -3.004 & 0.030 \\
L*2 & 0.184 & 0.059 & 3.958 & 3.116 & 0.026 \\
Constant & 16.296 & 1.731 & & 9.412 & 0.000 \\
\hline
\end{tabular}

- Testing goodness of fit of regression model: according to Tab.10, $\bar{R}^{2}=0.526$, Eq. (5) fits sample data relatively good.

- Significance testing of regression model: according to Tab.11, Sig. is 0.067, and less than significance level 0.1 , so Eq. (5) is statistically significant at significance level of 0.1 , and can be used to describe the correlation between the straight line length and PNN50

- Significance testing of regression coefficient: according to Tab.12, Sig. of $L$ is 0.030 and Sig. of $L^{2}$ is 0.026 , they are both less than 0.05 , so each coefficient is statistically significant, i.e. the effect of $L$ and $L^{2}$ on PNN50 is significant.

\section{The Maximum Straight Line Length for Prairie Highway}

According to the established model as Eq. (3) showing, the regression line between the straight line length and $S D N N$ is drawn as Fig.5, which is quadratic parabola with upward opening. The regression line between the straight line length and SDSD ( $P N N 50$ ) is similar to Fig.5. It can be seen from Fig.5 that $S D N N$, $S D S D$, PNN50 gradually decrease with the increase of the straight line length, but when they reduce to a certain extent, they go up. We can infer that the driver's attention is gradually distracted, and after it comes to a tipping point, it is gradually focused with the increase of the straight line length. We can make the following explanations for above phenomenon: when the driver just enter the straight line from a curve, the driver's attention is focused due to the curve turn stimulus, and the attention is gradually distracted with the increase of the straight line length because of monotonous alignment, monotonous landscape and little information stimulus, then the attention is centralized again because the driver is aware of the condition of his attention being distracted.

SDNN

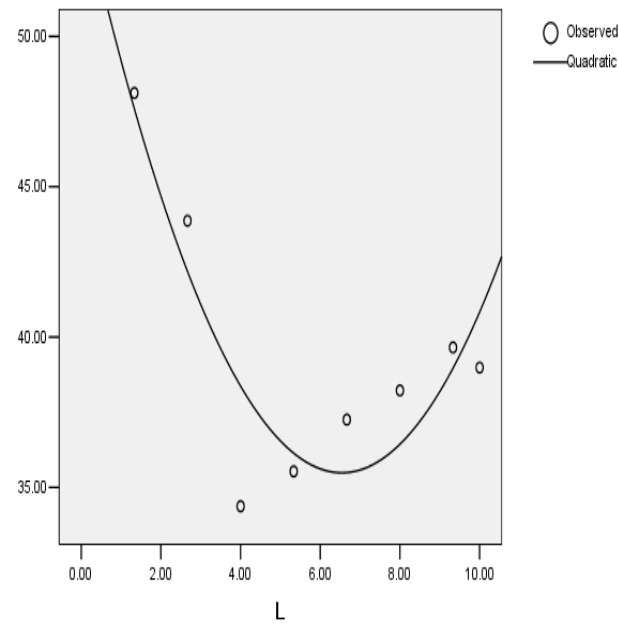

Fig.5. The regression line between the straight line length and $S D N N$

The driver's attention is the most distracted at the lowest point of the regression line. If the straight line length reaches abscissa of the lowest point and meeting an emergency, a traffic accident may take place because the driver almost has no time to react. So the straight line length should not exceed this length, i.e. the lowest point's abscissa is the maximum straight line length for prairie highway within which the driver could travel with proper attention level.

The lowest point's coordinate of the three regression lines between the straight line length and SDNN, SDSD, PNN50 respectively are computed and shown as (6.61, 35.47), (5.17, 29.74) and (5.67, 10.37). The maximum straight line length is considered to be $6.61 \mathrm{~km}$ according to the regression model between the straight line length and SDNN ; the maximum straight line length is considered to be $5.17 \mathrm{~km}$ according to the regression model between the straight line length and $S D S D$; the maximum straight line length is considered to be $5.67 \mathrm{~km}$ according to the regression model between the straight line length and PNN50. Taking the minimum value 
among $6.61 \mathrm{~km}, 5.17 \mathrm{~km}$, and $5.67 \mathrm{~km}$, it can be concluded that the maximum straight line length for prairie highway within which the driver could travel with proper attention level is $5.17 \mathrm{~km}$, after taking the integer value, is $5 \mathrm{~km}$.

\section{Conclusions}

Aiming at the phenomenon that the attention of the driver traveling along a long straight line of prairie highway is easy to be distracted due to the over-long and monotonous straight line, and a traffic accident may occur when meeting an emergency, the correlation of straight line length and driver's attention is studied through laboratory simulation experiment and regression analysis, and regression models between straight line length and $S D N N, S D S D, P N N 50$ are established in this paper.

By analyzing the established models, we can infer that with the increase of the straight line length, the driver's attention is gradually distracted, and after it comes to a tipping point, it is gradually focused. And it can be theoretically concluded that the maximum straight line length for prairie highway within which the driver could travel with proper attention level is $5 \mathrm{~km}$.

In term of prairie highway construction, the straight line whose length reaches $5 \mathrm{~km}$ should be connected with a curve, and the number of curve should be increased to make the driver's attention centralized to guarantee safe driving. In term of Intelligent Transportation, the $5 \mathrm{~km}$ could be an input to vehicle monitoring system as one of the in-vehicle support systems, ${ }^{28}$ i.e. when the straight line length reaches $5 \mathrm{~km}$, this monitoring system will warn the driver with sound or light to make the driver's attention centralized.

\section{Acknowledgements}

This research was supported by the National High Technology Research and Development Program of China (No.2007AA11Z210), and the National Nature Science Foundation of China (No. 50978057).

\section{References}

1. G. Z. Cheng and Y. L. Pei, Study on reasonable value of the largest length of straight line section on freeway, Journal of Highway and Transportation Research and Development, 25(8) (2008) 142-145.

2. L. N. Zheng, J. T. Hao, S. H. Zuo and Y. Zhang, Research on the maximum linear model and traffic safety, Journal of
Heilongjiang Hydraulic Engineering College, 34(3) (2007) 74-75.

3. B.Q. Wang, Study on the long straight line of horizontal alignment and its limit, Southwest Highway, (4) (1996) 20-24.

4. R. M. Xiao, W. G. Yun and T. B. Xu, Driving safety on long-even-straight-line road on highland, Journal of Chang an University (Natural Science Edition), 27(3) (2007) 76-79.

5. W. G. Yun, Driving safety study on the long-even straight line road, Master Thesis of Chang an University, (Xian, 2008).

6. B. J. Chung, J.B. Park, J.Y. Kim and M. Chang, Limit length evaluation of tangent on freeway according to driver's physiological response, in TRB annual meeting (2001), pp.1-8.

7. F. T. Ren, Traffic Engineering Psychology, (Beijing Technology University Press, Beijing, 1993).

8. K. Zheng, L. S. Jiang, J. Rong and F. T. Ren, Study on mental and physiological effects of horizontal radius of expressway on driving reaction, Journal of Highway and Transportation Research and Development, 21(5) (2004) 5-7.

9. K. Zheng, J. Rong and F. T. Ren, Analysis of the relation among driving tenseness of drivers, horizontal radius and driving speed, China Civil Engineering Journal, 36(7) (2003) 57-60.

10. S. L. Wang, J. C. Chen, X. M. Liu and J. Rong, Research on safety slope grade based on driver's psychological response, Journal of Highway and Transportation Research and Development, 24(2) (2007) 126-129.

11. Y. Yan and H. X. Liu, Study on effect of alignment index of longitudinal slope sections of mountain roads on drivers' psychology and physiology, Journal of Wuhan University of Technology (Transportation Science \& Engineering), 32(6) (2008) 1013-1016.

12. X. D. Pan and Y. H. Yin, Research on the safety running sight distance at the small radius curve part of mountainous highways based on ergonomics, Journal of East China Jiaotong University, 24(2) (2007) 55-57.

13. D. C. Zikovitz and L. R. Harris, Head tilt during driving, Ergonomics, 42(5) (1999) 740 - 746.

14. K. S. Rutley and D. G. W. Mace. Heart rate as a measure in road layout design, Ergonomics, 15(2) (1972) 166-173.

15. P. Richter, T. Wagner, R. Heger and G. Weise, Psychophysiological analysis of mental load during driving on rural roads-a quasi-experimental field study, Ergonomics, 41(5) (1998) 593 - 609.

16. W. J. Horrey, C. D. Wickens and K. P. Consalus, Modeling drivers' visual attention allocation while interacting with in-vehicle technologies, Journal of Experimental Psychology: Applied, 12 (2006) 67-78.

17. W. H. Wang, A digital driving system for smart vehicle, IEEE Intelligent Systems, 17(5) (2002) 81-83.

18. R. Sukthankar, J. Hancock and C. Thorpe, Tactical-level Simulation for Intelligent Transportation Systems, Mathematical and Computer Modelling, 27(1998) 19-24.

19. C. Q. Li and W. W. Dong, Analysis of heart rate variability and its application in neurology, Acta Universitatis 
Seientiae Medieinae Chongqing, 25(1) (2000) 101-103.

20. H.Z. Cheng, Study on heart rate variability, Chinese Journal of Internal Medicine, 34(5) (1995) 291-292.

21. C. Y. Song, Q. L. Zhang, S. W. Zhang and Y. L. Liu, Effect of age and average heart on heart rate variability, Journal of Electrocardiology, 15(3) (1996) 69-70.

22. W. H. Qi, Prospect of applying heart rate variability to cure angiocardiopathy, Chinese Journal of Cardiology, 23(1) (1995) 7-8.

23. L. Fu and H. J. Chi, Applying and evaluation of heart rate variability, Chinese Journal of Practical Internal Medicine, 21(5) (2001) 269-271.

24. L. Liu, Study on application of heart rate variability in vehicle driver fatigue detecting, Master Thesis of Chongqing University, (Chongqing, 2007).

25. J. Sun and G. S. Li, The effect of temperature on heart rate and heart rate variability, Progress of Anatomical Sciences, 13(1) (2007) 87-90.

26. D.P. Xiao, The study on HRV clinic analysis technology, Master Thesis of Chongqing University, (Chongqing, 2004).

27. Q.P. Xu and Y.F. Zhang, Heart rate variability in diabetic autonomic neuropathy, Journal of Zhejiang University (Medical Sciences), 30(3) (2001) 115-118.

28. W.H. Wang, F.G. Huo, H.C. Tan and H. Bubb, A framework for function allocation in intelligent driver interface design for comfort and safety, International Journal of Computational Intelligence Systems, 3(5) (2010) 531-541. 